\title{
Preference for Immunotherapy with Tablets by People with Allergic Rhinitis
}

\author{
Mike Tankersley ${ }^{1,2}$ \\ Tonya Winders (D) $^{3,4}$ \\ Mark Aagren ${ }^{5}$ \\ Henrik Brandi $\mathbb{1 D}^{5}$ \\ Mikkel Hasse Pedersen (1D ${ }^{6}$ \\ Anne Sofie Ledgaard \\ Loftager (D) $^{6}$ \\ Mette Bøgelund (DD ${ }^{6}$ \\ 'Departments of Medicine, Pediatrics and \\ Otolaryngology, University of Tennessee \\ Health Science Center, Memphis, TN, \\ USA; ${ }^{2}$ The Tankersley Clinic, Memphis, \\ TN, USA; ${ }^{3}$ Allergy \& Asthma Network, \\ Vienna, VA, USA; ${ }^{4}$ Global Allergy \& \\ Airways Patient Platform, Vienna, Austria; \\ ${ }^{5}$ Department of Global Market Access \& \\ Public Affairs, ALK, Hørsholm, Denmark; \\ ${ }^{6}$ Incentive Denmark, Holte, Denmark
}

Correspondence: Mette Bøgelund Tel +452916 I222

Email mb@incentive.dk
Background: People with allergic rhinitis (AR) who are not controlled on conventional therapy can be treated using allergy immunotherapy (AIT) administered as tablets, injections or drops. In the US, the use of sublingual immunotherapy as tablets (SLIT-tablets) is limited in comparison to subcutaneous immunotherapy (SCIT).

Objective: This study investigated patients' preference for SLIT-tablets vs monthly or weekly SCIT from a US patient perspective.

Methods: We carried out a discrete choice experiment (DCE) consisting of two blocks with eight choice sets. Adults and caregivers of children with moderate-to-severe AR were included if they had not previously or were not currently receiving AIT. Three attributes were included in the design: the mode and frequency of administration, the risk of systemic reactions and the co-payment.

Results: A total of 724 adults with AR and 665 caregivers of children with AR were included in the study. Both adults and caregivers had a significant preference for SLIT-tablets compared with both weekly and monthly injections and for less risk of anaphylactic shock. Caregivers were more risk-averse than adults when choosing their treatment, and the younger the child, the more risk-averse the caregiver. The preference for SLIT-tablets was found for both monoallergic and polyallergic adults and caregivers of monoallergic and polyallergic children. Respondents not wanting AIT for free were more risk-averse than those indicating that they wanted AIT for free.

Conclusion: Our findings suggest that SLIT-tablets is the preferred route of administration for AIT among adults and caregivers of children with AR.

Keywords: allergic rhinitis, allergy immunotherapy, discrete choice experiment, patient preferences, subcutaneous immunotherapy, sublingual immunotherapy

\section{Introduction}

Allergic rhinitis (AR) is a non-infectious immunoglobulin E (IgE) mediated inflammatory disease affecting the nasal mucous membranes. ${ }^{1}$ AR affects $10 \%-20 \%$ of US adults ${ }^{1}$ and closer to $40 \%$ of US children. ${ }^{5}$ AR is associated with other diseases such as asthma, atopic dermatitis and conjunctivitis. ${ }^{2,3}$ AR has a negative impact on quality of life, sleep, concentration and work productivity. ${ }^{2,4}$ Work impairment is correlated with the severity of AR. ${ }^{4}$

Management of AR often consists of allergen avoidance, pharmacological management with symptom-relieving medication or allergy immunotherapy (AIT). Antihistamines and intranasal corticosteroids are recommended as first-line therapy. ${ }^{1,6}$ AIT is recommended as an option for people with a confirmed IgEmediated disease who are uncontrolled on symptomatic treatment ${ }^{4,7,8}$ such as 
corticosteroids or antihistamines. ${ }^{9}$ Contrary to symptomatic treatment, AIT modifies the immunologic pathways that cause the allergic response. AIT has proven to provide long-term desensitization against allergens even after the end of treatment (3-5 years). ${ }^{10-12}$ AIT can be administered as sublingual immunotherapy (SLIT), as either tablets (SLIT-tablets) or drops, or as subcutaneous immunotherapy (SCIT). ${ }^{13}$ However, SLIT-drops are not approved by the US Food and Drug Administration (FDA); ${ }^{14,15}$ therefore, we restrict the focus of this article to SLIT-tablets and SCIT. An estimated $2 \%-9 \%$ of people in the US with AR are treated with AIT. ${ }^{16}$

The mode of administration of SCIT and SLIT-tablets differs. The initial dose of SLIT-tablets is administered in a medical setting, but the following doses are administered daily at home by the patient. SCIT, on the other hand, is always administered by a healthcare professional, starting with an up-dosing phase, where the injections are given once or twice a week, and continuing with a maintenance phase, where the injections are given every second or fourth week. ${ }^{9,17}$ Throughout the up-dosing phase, injections contain increasing amounts of allergen. SLIT-tablets are administered in the same dose throughout the treatment course and does not require an up-dosing phase. ${ }^{18,19}$

Evidence of patient preference for SCIT or SLITtablets is lacking, and current literature is inconclusive on patient preference. Chester et $\mathrm{al}^{22}$ asked patients to rank four different routes of administration and revealed that patients preferred SLIT-tablets to SCIT ( $p<0.0001$ ). Damm et $\mathrm{al}^{23}$ investigated patients' preferences for SCIT or SLIT-tablets using a discrete choice experiment (DCE) in a German population. The results were mixed, as the DCE revealed a preference for SCIT, whereas the respondents indicated preferences for SLIT-tablets when asked directly. In addition, the study assumed independency of the mode of administration, the local side effects, and the number and duration of visits to a physician, but it is likely that patients do not experience these factors as independent of each other in a clinical setting.

During the last decade the use of SLIT-tablets have been increasing as four SLIT-tablets have been approved by the FDA since 2014, however, the use of SLIT-tablets in the US is still limited in comparison to SCIT. ${ }^{24}$

More evidence is necessary to understand patients' preferences of SCIT or SLIT-tablets. The objective of this study was to evaluate patients' preferences for SCIT vs SLIT-tablets in the US, in both adults with AR and caregivers of children with AR.

\section{Methods}

We have conducted a survey assessing AIT preferences. Adults and caregivers of children (aged 5-17 years) with symptomatic AR of at least moderate severity who are not currently on or have not previously tried AIT were included in the study. Caregivers of a child with AR were invited to answer the survey on behalf of their child. The survey covered the following:

Allergy-specific questions (allergy types, symptoms and medication use)

Quality of life using EQ5D-5L and visual analog scale (VAS)

Participants' preferences using a DCE design

Socioeconomic questions

Following approval from IntegReview Institutional Review Board (IRB), Texas, US, the survey was distributed through email panels in collaboration with Kantar/ Gallup to access a large group of US adults with AR and caregivers of children with AR. The participants were invited to complete the survey online. Informed consent was obtained from all participants in the beginning of the online survey. Data were collected from July 22, 2020, to November 7, 2020.

\section{Discrete Choice Experiment}

A DCE is a stated preference method that can be used to elicit an individual's preference for different policies, services and interventions. The individuals are presented with several paired alternatives and choose their preferred alternative. Each alternative comprises a combination of socalled treatment attributes with different levels. In a DCE, the respondents are asked to select the alternative with the combination of attributes and levels that maximizes their utility, ${ }^{25-27}$ which enables the researcher to estimate the respondents' relative preferences. The stated preference method has been recognized by the FDA as useful for understanding patient preferences. ${ }^{28}$

Respondents were introduced to all treatment attributes before the DCE questions were presented. The attributes and the associated levels included in the DCE are shown in Table 1.

Table 2 shows an example of a DCE question.

\section{Administration}

The administration attribute had three levels, depending on the mode and frequency of AIT administration: (1) tablets taken at home every day with annual visits to an allergy clinic; (2) weekly injections at an allergy clinic; and (3) 
Table I Attributes and Levels in the Discrete Choice Experiment

\begin{tabular}{|l|l|}
\hline Main Attributes & Levels \\
\hline Administration & $\begin{array}{l}\text { Tablet at home every day with annual } \\
\text { visits to an allergy clinic } \\
\text { Weekly injections at an allergy clinic } \\
\text { Monthly injections at an allergy clinic }\end{array}$ \\
\hline $\begin{array}{l}\text { Risk of a systemic } \\
\text { reaction }\end{array}$ & $\begin{array}{l}\text { No risk at all } \\
\text { I out of } 200,000 \\
100 \text { out of } 200,000\end{array}$ \\
\hline $\begin{array}{l}\text { Cost per month (co- } \\
\text { payment), USD }\end{array}$ & $\begin{array}{l}0 \\
20 \\
70 \\
150\end{array}$ \\
\hline
\end{tabular}

Table 2 Example of a DCE Question

\begin{tabular}{|l|l|l|}
\hline & Treatment A & Treatment B \\
\hline Administration & $\begin{array}{l}\text { Tablet at home every day } \\
\text { with annual visits to an } \\
\text { allergy clinic }\end{array}$ & $\begin{array}{l}\text { Monthly } \\
\text { injections at an } \\
\text { allergy clinic }\end{array}$ \\
\hline $\begin{array}{l}\text { Risk of a } \\
\text { systemic } \\
\text { reaction }\end{array}$ & I out of 200,000 & $\begin{array}{l}100 \text { out of } \\
200,000\end{array}$ \\
\hline $\begin{array}{l}\text { Cost per month } \\
\text { (co-payment), } \\
\text { USD }\end{array}$ & 150 & 20 \\
\hline $\begin{array}{l}\text { Which would } \\
\text { you prefer? }\end{array}$ & & \\
\hline
\end{tabular}

Abbreviation: DCE, discrete choice experiment.

monthly injections at an allergy clinic. Contrary to the study by Damm et al, ${ }^{23}$ the mode of administration, the frequency of the visits at the clinic and the local site reactions were assumed to be dependent. The mode of administration and the frequency were gathered into one administration attribute. The site reaction from the injections and the tingling/swelling in the mouth from the SLIT-tablets were explained in the introduction to the DCE questions.

\section{Risk of Systemic Reactions}

AIT is associated with a low risk of a severe systemic reaction and SLIT-tablets are considered to have a lower risk compared to SCIT. ${ }^{19}$ Possible reactions include an itchy rash, throat or tongue swelling, shortness of breath, vomiting, lightheadedness, or low blood pressure. Systemic reactions are potentially serious or even life- threatening if not treated immediately. Therefore, patients are monitored at the clinic the first time they receive SLITtablets and every time they receive SCIT.

The risk of experiencing a systemic reaction was sourced from Dahl et al. ${ }^{29}$ The study revealed 21 cases of systemic reactions out of 47,000 patient treatment years on SCIT and 1 case of systemic reaction out of 134,000 patient treatment years on SLIT-tablets. This indicates that the risk is approximately 60-fold higher for SCIT compared with SLIT-tablets. However, to make it easier for respondents to comprehend the level of risk, the risk attribute had two levels, with a 100-fold difference and a "no risk" level.

\section{Cost (Co-Payment) per Month}

A price attribute was included to assess patients' willingness to pay (WTP) for AIT. The attribute had four possible values: USD 0, USD 20, USD 70 and USD 150. The results of the annual Employer Health Benefits survey conducted by the Kaiser Family Foundation showed the average co-payment among employees with prescription drug coverage was between USD 11 and USD 105 for plans with three or more tiers. ${ }^{30}$ These levels were therefore included in the study in order to cover the variation in US patients' monthly co-payments for AIT (for employees with health insurance).

\section{Design of the DCE Questions}

A full factorial choice design would give rise to $(3 \times 3 \times$ $4)^{2}=1296$ possible combinations of attributes for the DCE module in the survey. In line with common practice, choice sets were selected from these combinations based on statistical efficiency. To improve the efficiency of data collection, a D-efficient design with Bayesian priors was generated using the NGENE software.

In order not to overburden the participants with too many questions while still covering a large spectrum of possible choice scenarios, the participants were randomly assigned to one of two blocks in the survey. Each block included eight sets of two possible choice scenarios.

\section{The Pilot of the Study}

The pilot phase was carried out in July 2020 with 39 adults and 43 caregivers to test the relevance and accuracy of the survey. As this phase did not result in modifications, these respondents were included in the final analyses. 


\section{Exclusion and Data Validation}

Respondents who finished the eight DCE questions in less than 30 seconds were excluded from the estimation of preference results.

Before the statistical analysis, data were validated by checking the answers for errors and consistency.

\section{Statistical Analysis}

Data from questions the respondents answered before and after the DCE module were analyzed using univariate descriptive statistics (means, medians, modes, and frequencies).

A conditional logit model was used to determine the coefficients of the included attributes and their levels in choice of preferred treatment. The probability of choosing alternative $\mathrm{j}$ from $\mathrm{n}_{\mathrm{j}}$ choices in the choice scenario $\mathrm{i}$ can be described as:

$$
P(j)=\frac{\exp \left(X_{i j}^{\prime} \beta\right)}{\sum_{k \in C_{i}} \exp \left(X_{i k}^{\prime} \beta\right)}
$$

The confidence intervals (CIs) could not be derived directly from the conditional logit estimates, as the estimates are calculated as ratios of two stochastic variables. Therefore, bootstrapping was used to determine the $95 \%$ CI. Following standard practice, 10,000 replications were performed. The statistical analysis was carried out in SAS Version 9.4 (SAS Institute Inc., Cary, NC, US).

Sub-analyses were conducted to see whether preferences differed between subgroups. We stratified according to gender (male vs female), number of allergies (mono- vs polyallergic), child's age (children 5-12 years vs children 13-17 years) and whether or not respondents indicated that they wanted AIT for free.

\section{Results}

\section{Sample}

Adults

A total of 737 adults with symptomatic AR of moderate or higher severity who are not currently trying or have not previously tried AIT started the survey. Of those, 13 only partly completed the survey and were therefore excluded from the analysis, leaving 724 respondents. Eight completed the DCE module in less than 30 seconds, and as a result their responses were not included in the preference estimates. A flowchart of the study population is presented in Figure 1.
The adult respondents were on average 52 years old, two-thirds were female and their median EQ-5D score was 0.83 . The primary allergies were related to pollen, and $22 \%$ suffered from asthma (Table 3).

\section{Caregivers}

Six hundred and seventy-two caregivers started the survey on behalf of their child with symptomatic AR of moderate or higher severity who are not currently trying or have not previously tried AIT. Seven caregivers only partly completed the survey and were therefore excluded from the analysis, leaving 665 caregivers. Fourteen completed the DCE module in less than 30 seconds, and therefore their responses were not included in the preference estimates (Figure 1).

The caregivers were on average 43 years old, and $72 \%$ of the caregivers of children with AR were female. The children with AR, which the caregivers responded on behalf of, were on average 12 years old and $54 \%$ of the children with AR were female. The primary allergies in the children were also related to pollen, and $22 \%$ of the children suffered from asthma (Table 3).

\section{Preferences}

Both adults and caregivers have a significant preference for SLIT-tablets over monthly or weekly injections $(\mathrm{p}<0.001)$ and a significant preference for less risk of anaphylactic shock $(\mathrm{p}<0.001)$. This is in line with the answers from the questionnaire. When respondents were asked directly, 91\% of adults and $92 \%$ of caregivers indicated that they preferred SLIT-tablets to weekly injections. The results also revealed that caregivers of children with AR have a higher preference for SLIT-tablets and were more risk-averse when choosing their treatment compared with adults with AR. The estimates from the conditional logit regression analysis are shown in Table 4. The table shows that all estimates are significant and therefore predictive for choice of AIT.

In Figure 2, we have shown the disutility for the different attributes relative to receiving SLIT-tablets with no risk of systemic reactions, which was the preferred combination for both adults and caregivers of children. The larger the disutility, the less preferred is the combination. The least preferred combination was weekly injections with a risk of systemic reactions of 100/200,000 for both adults and children.

\section{Sub-Analyses}

The results from the sub-analyses for adults with AR and caregivers of children with AR are shown in Tables 5 and 


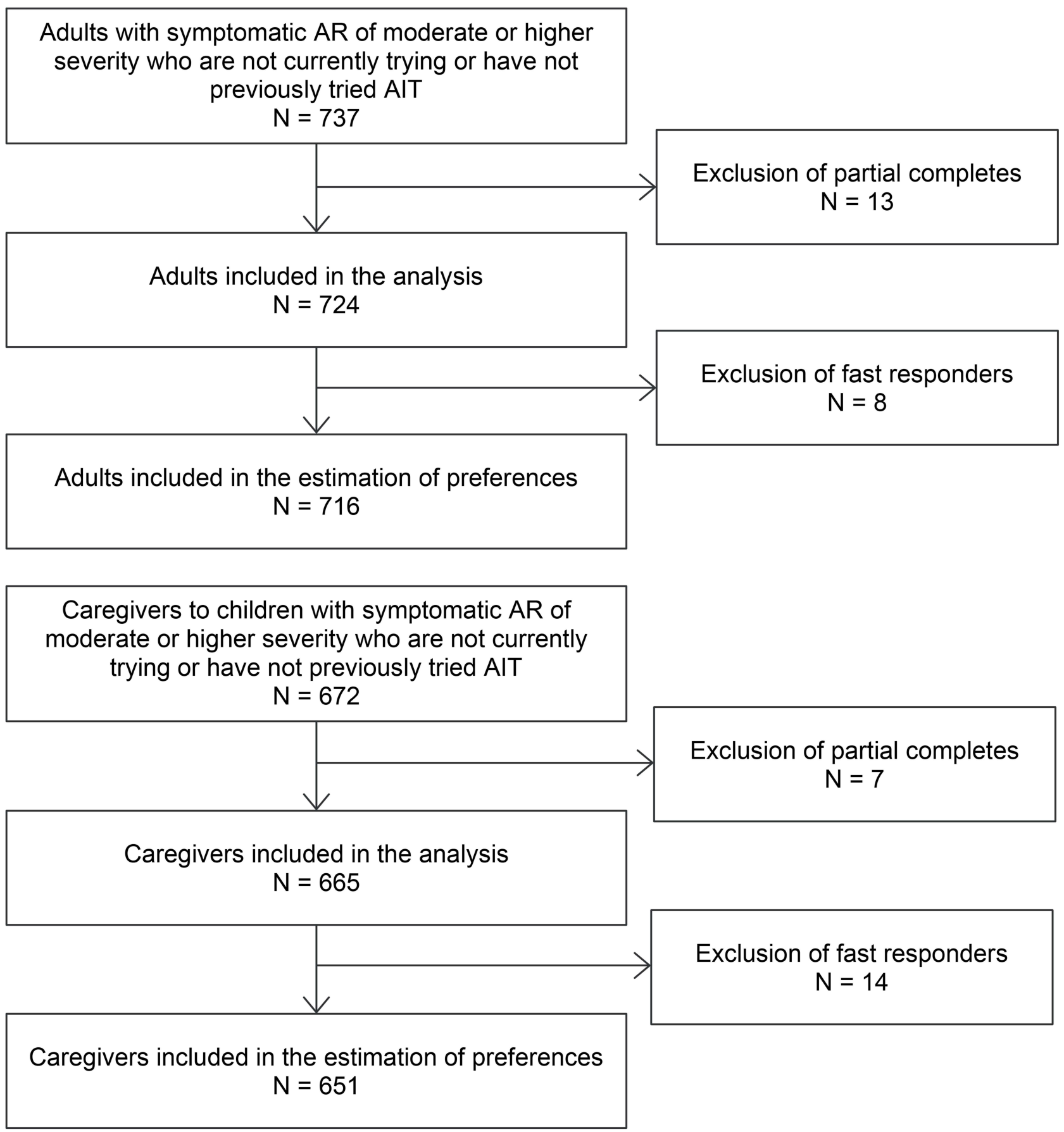

Figure I Flowchart of the study population selection.

6 , respectively. Results revealed that the younger the child is, the more risk-averse caregivers are, as the preference for having less risk was higher for caregivers of children ages 5 to 12 compared with caregivers of children ages 13 to 17 . Both mono- and polyallergic adults and caregivers of both mono- and polyallergic children have a higher preference for SLIT-tablets compared with injections. Furthermore, the preference for SLIT-tablets is highest for monoallergic adults and caregivers of monoallergic children compared with polyallergic adults and caregivers of polyallergic children.

Before they received the DCE questions, the respondents were asked to indicate whether they would like AIT as daily tablets, would like AIT as weekly injections, or would rather not receive either even if they could get the treatments for free. In a comparison of adults and 
Table 3 Demographics and Disease-Specific Characteristics

\begin{tabular}{|c|c|c|}
\hline & Adults & Caregivers Answering for Their Children \\
\hline \multicolumn{3}{|l|}{ Demographics of adults and caregivers } \\
\hline Male & $256(35 \%)$ & $185(28 \%)^{a}$ \\
\hline Female & $468(65 \%)$ & $480(72 \%)^{a}$ \\
\hline Mean age, years & 52 & $43^{\mathrm{a}}$ \\
\hline Median household income category, USD & $40,000-49,999$ & $50,000-74,999^{a}$ \\
\hline Median EQ-5D score & 0.83 & - \\
\hline \multicolumn{3}{|l|}{ Age of allergy debut and diagnosis } \\
\hline Mean age when experienced first symptoms, years & 21.3 & 5.7 \\
\hline Mean age of diagnosis, years & 22.0 & 6.3 \\
\hline \multicolumn{3}{|l|}{ Comorbidities } \\
\hline Asthma & $157(22 \%)$ & $147(22 \%)$ \\
\hline \multicolumn{3}{|l|}{ Allergies affecting the respondents the most } \\
\hline Allergies towards animals (dogs, cats, horses, etc.) & $60(8 \%)$ & $102(15 \%)$ \\
\hline Allergies related to pollen (grasses, weeds, trees, etc.) & $539(74 \%)$ & $474(71 \%)$ \\
\hline Allergies related to house dust mites & $56(8 \%)$ & $56(8 \%)$ \\
\hline Other year-round allergies (cockroaches, mold, etc.) & $69(10 \%)$ & $33(5 \%)$ \\
\hline \multicolumn{3}{|l|}{ Allergy symptoms } \\
\hline Stuffy nose, runny nose, sneezing or post-nasal drip & $694(96 \%)$ & $640(96 \%)$ \\
\hline Itchy, red or watery eyes & $571(79 \%)$ & $505(76 \%)$ \\
\hline Shortness of breath, chest tightness or pain, coughing or wheezing & $231(32 \%)$ & $192(29 \%)$ \\
\hline Itchy skin reactions or skin pain or redness of the skin & 197 (27\%) & $277(42 \%)$ \\
\hline \multicolumn{3}{|l|}{ Mono- vs polyallergic } \\
\hline Monoallergic & $253(35 \%)$ & $198(30 \%)$ \\
\hline Polyallergic & $471(65 \%)$ & $467(70 \%)$ \\
\hline \multicolumn{3}{|l|}{ Medication use } \\
\hline Oral antihistamines & $558(81 \%)$ & $602(91 \%)$ \\
\hline Decongestants & $389(54 \%)$ & $424(64 \%)$ \\
\hline Nasal sprays and drops & $415(57 \%)$ & $397(60 \%)$ \\
\hline Eye drops & $395(55 \%)$ & $311(47 \%)$ \\
\hline
\end{tabular}

Note: ${ }^{\text {a}}$ Caregivers demographics.

caregivers who indicated they wanted AIT as either tablets or injections with those who indicated they did not want AIT, results revealed that respondents who wanted AIT had an even higher preference for SLIT-tablets than those who did not want AIT. Furthermore, respondents who did not want AIT were more risk-averse compared with respondents who wanted AIT.

\section{Discussion}

This study revealed a significant preference for AIT administered as tablets compared with either monthly or weekly injections and a preference for a lower risk of systemic reactions - a preference expressed by both adults with AR and caregivers of children with AR. Our results confirm the findings from Chester et $\mathrm{al}^{22}$ that the majority of patients prefer SLIT-tablets rather than SCIT. The difference between this study and the study by Damm et $\mathrm{al}^{23}$ was that this study assumed that the mode of administration was linked to local site reactions and to the frequency of administration, whereas the study by Damm et $\mathrm{al}^{23}$ did not link these factors. This difference can explain the different results. The studies were also conducted in different countries (Germany vs the US), and because preference can vary among different populations, it was 
Table 4 Estimates from the Conditional Logit Regression Analysis

\begin{tabular}{|c|c|c|c|}
\hline & Estimate & Standard Error & P-value \\
\hline \multicolumn{4}{|l|}{ Adults with AR } \\
\hline Tablets vs weekly injections & 1.2208 & 0.0500 & $<0.0001$ \\
\hline Monthly injections vs weekly injections & $0.500 \mathrm{I}$ & 0.0455 & $<0.0001$ \\
\hline No risk vs risk $100 / 200,000$ & 1.0266 & 0.0487 & $<0.0001$ \\
\hline Risk $1 / 200,000$ vs risk $100 / 200,000$ & 0.4364 & 0.0436 & $<0.0001$ \\
\hline Monthly payment in USD & -0.0138 & 0.0005 & $<0.0001$ \\
\hline \multicolumn{4}{|l|}{ Caregivers of children with AR } \\
\hline Tablets vs weekly injections & 1.1466 & 0.0519 & $<0.0001$ \\
\hline Monthly injections vs weekly injections & 0.5276 & 0.0487 & $<0.0001$ \\
\hline No risk vs risk $100 / 200,000$ & 1.4603 & 0.0550 & $<0.0001$ \\
\hline Risk $\mathrm{I} / 200,000$ vs risk $100 / 200,000$ & 0.7358 & 0.0445 & $<0.0001$ \\
\hline Monthly payment in USD & -0.0110 & 0.0004 & $<0.0001$ \\
\hline
\end{tabular}

relevant to assess the preferences of the patients in the US specifically.

We found that respondents who indicated that they wanted AIT for free had slightly more severe AR and a higher consumption of allergy medication than respondents who did not want AIT. This could explain the finding that the $48 \%$ of respondents who wanted AIT had an even higher preference for SLIT-tablets compared with the respondents who did not want AIT. Presumably, these respondents were already used to taking daily medication for their allergies and therefore saw SLIT-tablets as an easy way of getting long-lasting relief from their allergy without additional effort. In addition to this, we found that respondents indicating that they wanted AIT had slightly higher household income, which therefore could also explain their preference for SLIT-tablets, since these respondents incur a higher opportunity cost from going to the clinic weekly or monthly to relieve their allergy compared with respondents indicating that they did not want AIT. Lastly, the respondents not wanting AIT were more risk-averse, which could indicate that they were reluctant to try AIT due to the risk of side effects.

The results from this study add to the current literature and understanding of patients' preferences for the different AITs. The DCE is recognized by the FDA as a method used for eliciting patient preference. Furthermore, the FDA suggests that patient preferences should be used in clinical product development and decision-making in order to create a patient-centered treatment approach. ${ }^{20}$ When treating patients, providers should also consider not only the cost but also the patient's preferences. Increasing the understanding of patients' preferences has the potential to improve the quality of care provided and patient adherence to treatment. ${ }^{21,31}$

Even though both adults with AR and caregivers of children with AR have a significant preference for SLIT-tablets, the majority of US patients are initiated on SCIT, regardless of whether they are monoallergic or polyallergic. The formulation of SLIT-tablets available in the US covers the most common respiratory allergies induced by timothy grass, ragweed, or house dust mites ${ }^{19}$ and could be a relevant treatment option for patients who prefer this type of AIT. Moreover, a study found that simultaneous administration of grass and ragweed SLIT-tablets within five minutes was well tolerated among patients following two weeks of sequential single SLIT. ${ }^{32}$

The findings emphasize the importance of shared decision-making between healthcare professionals and the patient as well as patient engagement for improved adherence and outcomes. A recent study indicates that $72 \%$ of healthcare providers have discussed AIT options with all patients who met the criteria. The study showed that the majority of health care providers did not use an AIT shared decision-making tool in the process. For that reason, it is important that information on patients' preferences for administration is conveyed to healthcare providers and considered for inclusion in available AIT shared decision-making tools. ${ }^{33-35}$

Results showed that the majority of the adults and children in this study were polyallergic $(>65 \%)$, a 


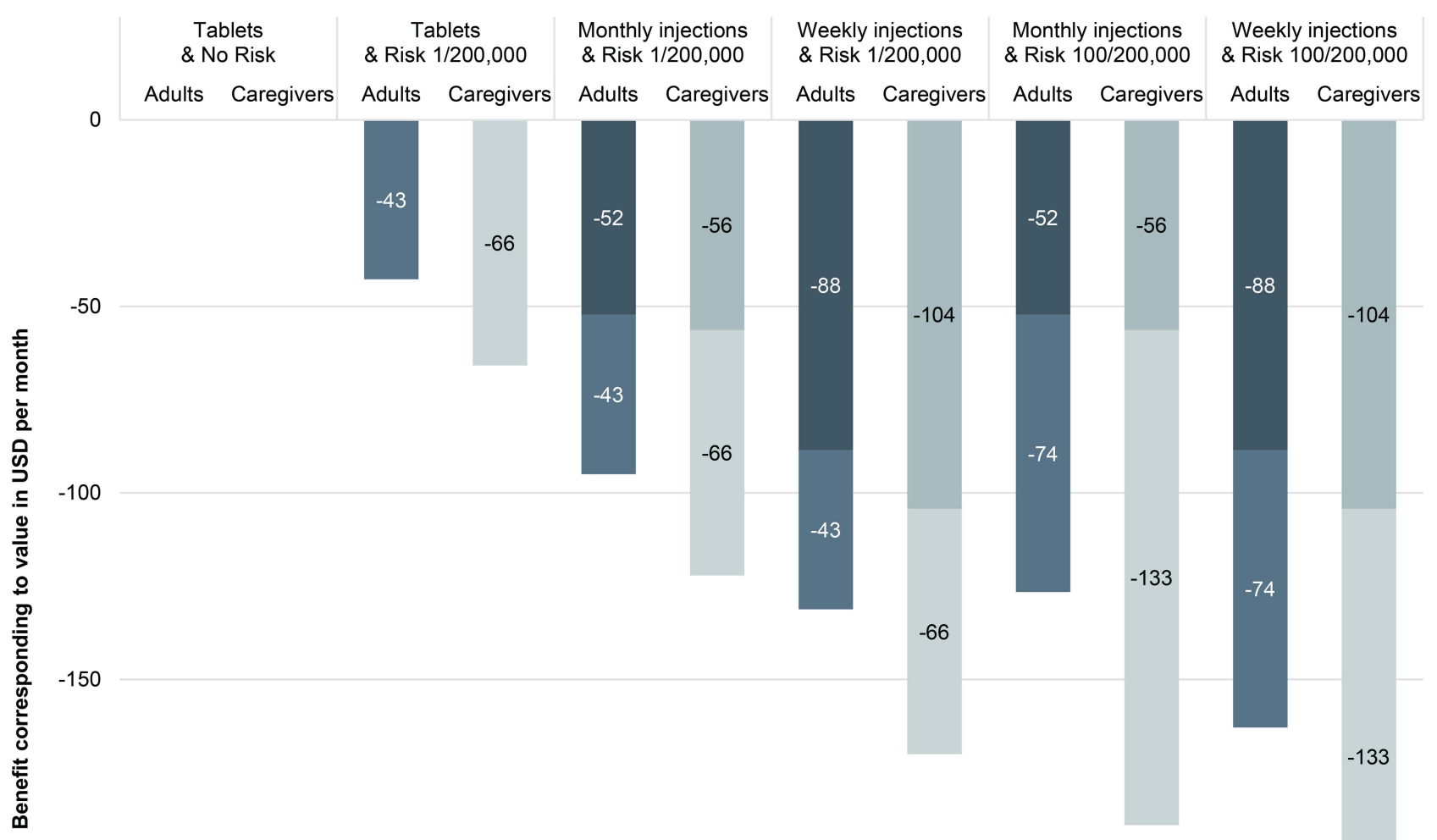

$-200$

$-250$

$-300$

$\square$ Administration Adults $\square$ Risk Adults $\llbracket$ Administration Caregivers $\backsim$ Risk Caregivers

Figure 2 Disutility for the various attributes corresponding to value in USD per month.

finding that is in line with findings from the National Health and Nutrition Examination Surveys in the US. ${ }^{36}$ It is a common approach in the US to treat the patient's sensitization to multiple allergens using a mixed-formulation SCIT, which could be a contributing factor for the high initiation on SCIT instead of SLIT-tablets. ${ }^{16,37}$ However, treating the primary allergy of polyallergic patients with AIT by relieving the symptoms from their primary allergy might also relieve the symptoms from their secondary allergies, but more clinical research is needed in this field. ${ }^{38,39}$

The present global health situation with the coronavirus (COVID-19) pandemic has brought attention to the importance of minimizing avoidable physical contact in the clinical setting. Initiating patients on SLITtablets instead of SCIT would reduce physical contact between the patient and the healthcare provider. This benefit may have affected patients' preferences, thus contributing to a higher preference for SLIT-tablets. On the other hand, such preferences may be unchanged after the pandemic.

\section{Conclusion}

Our findings suggest that SLIT-tablets are the preferred route of administration for AIT among adults and caregivers of children with AR. The findings highlight the 


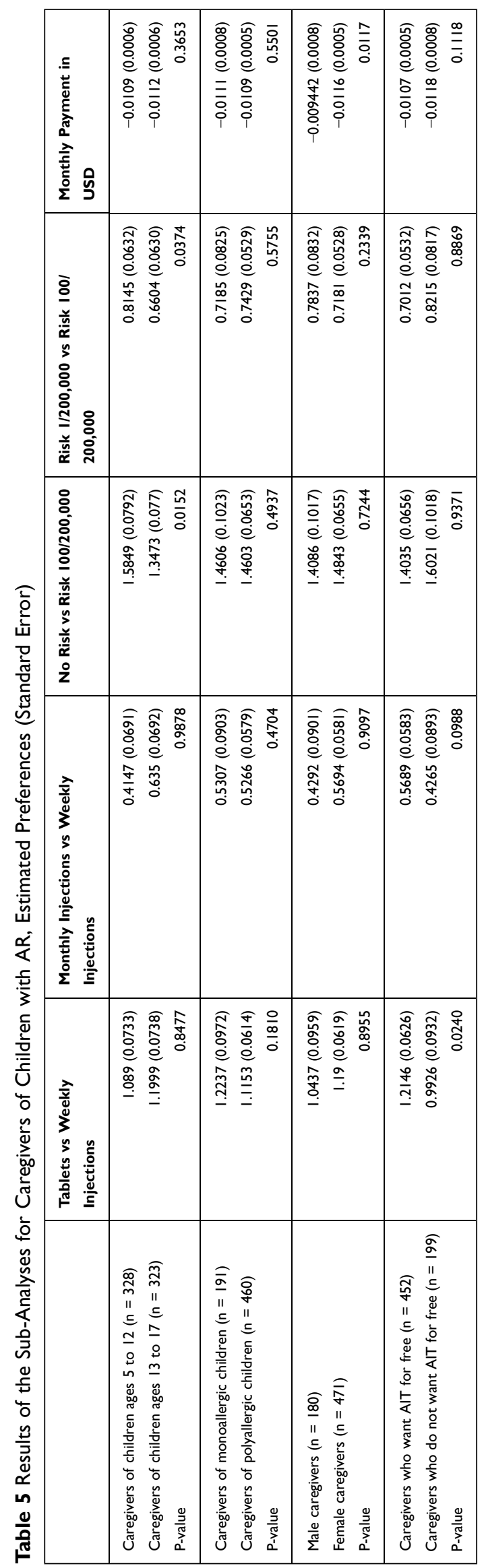

\begin{tabular}{|c|c|c|c|}
\hline 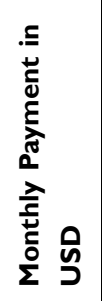 & 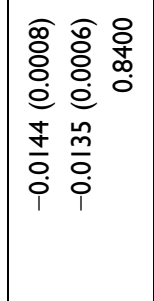 & 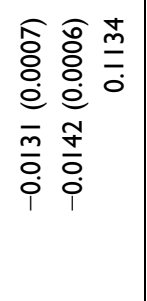 & 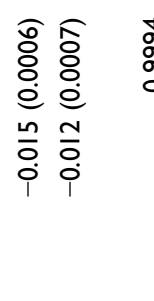 \\
\hline 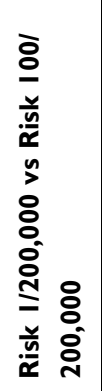 & 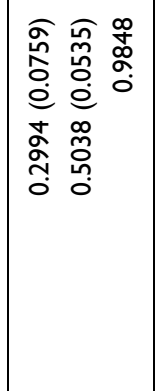 & 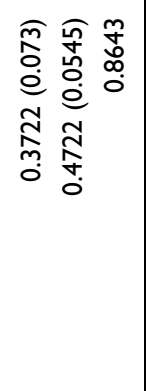 & 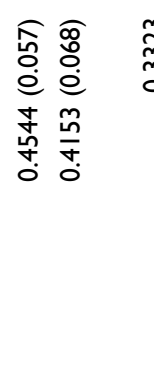 \\
\hline 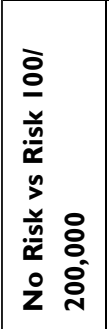 & 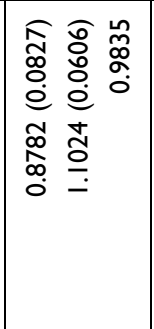 & 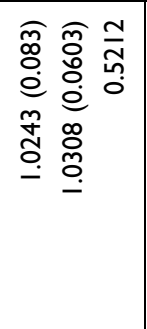 & 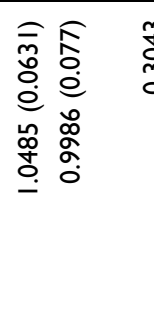 \\
\hline 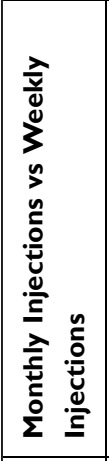 & 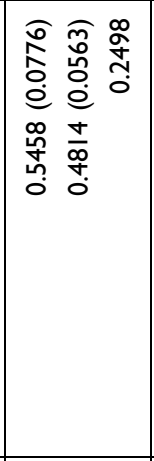 & 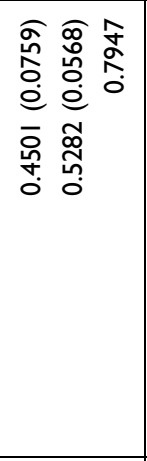 & 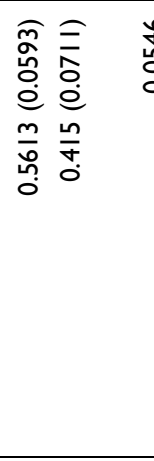 \\
\hline 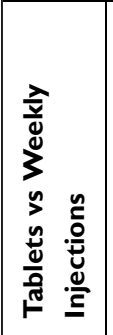 & 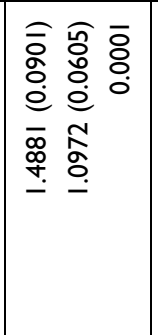 & 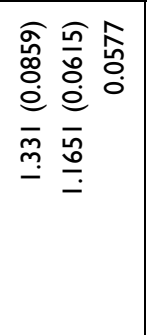 & 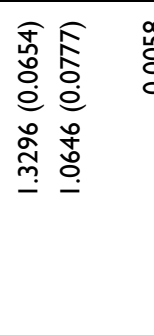 \\
\hline 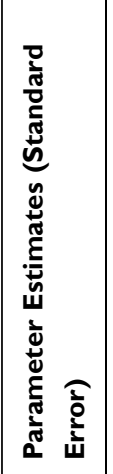 & 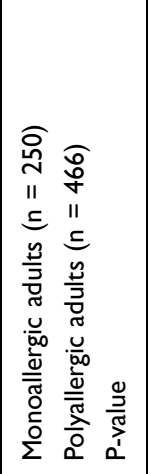 & 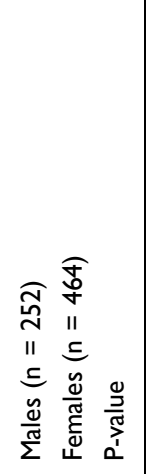 & 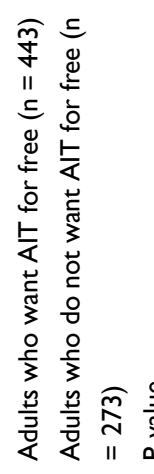 \\
\hline
\end{tabular}


importance of shared decision-making between healthcare professionals as well as patient engagement for improved adherence and outcomes.

\section{Abbreviations}

AIT, allergy immunotherapy; AR, allergic rhinitis; CI, confidence interval; COVID-19, coronavirus disease 2019; DCE, discrete choice experiment; FDA, Food and Drug Administration; IgE, immunoglobulin E; SCIT, subcutaneous immunotherapy; SLIT, sublingual immunotherapy; VAS, visual analog scale; WTP, willingness to pay.

\section{Ethics Approval and Informed Consent}

Informed consent was obtained from all respondents before starting the survey. The survey was approved by IntegReview Institutional Review Board, Texas, US (Protocol number: 2258, approved in April 2020). The study was conducted in accordance with the Declaration of Helsinki.

\section{Author Contributions}

All authors made a significant contribution to the work reported, whether that is in the conception, study design, execution, acquisition of data, analysis and interpretation, took part in drafting, revising, critically reviewing the article or in all these areas; gave final approval of the version to be published; have agreed on the journal to which the article has been submitted; and agree to be accountable for all aspects of the work.

\section{Funding}

This research was funded by ALK, Hørsholm, Denmark. ALK is a manufacturer of allergy immunotherapy.

\section{Disclosure}

Dr Tankersley is a speaker and consultant for ALK. Tonya Winders discloses that Allergy \& Asthma Network and Global Allergy \& Airways Patient Platform receive funding for unbranded disease awareness and education. Mark Aagren and Henrik Brandi are employees at ALK, Denmark. Mette Bøgelund, Mikkel Hasse Pedersen and Anne Sofie Ledgaard Loftager are employees at Incentive Denmark, which is a paid vendor of ALK, Denmark. The authors report no other conflicts of interest in this work.

\section{References}

1. Seidman MD, Gurgel RK, Lin SY, et al. Clinical practice guideline: allergic rhinitis. Otolaryngol Neck Surg. 2015;152(2):197-206. doi: $10.1177 / 0194599814561600$

2. Cingi C, Gevaert P, Mösges R, et al. Multi-morbidities of allergic rhinitis in adults: European Academy of Allergy and Clinical Immunology Task Force Report. Clin Transl Allergy. 2017;7(1):17. doi:10.1186/s13601-017-0153-z

3. Scadding GK, Kariyawasam HH, Scadding G, et al. BSACI guideline for the diagnosis and management of allergic and non-allergic rhinitis (Revised Edition 2017; First edition 2007). Clin Exp Allergy. 2017;47 (7):856-889. doi:10.1111/cea.12953

4. Bousquet J, Khaltaev N, Cruz AA, et al. Allergic Rhinitis and its Impact on Asthma (ARIA) 2008*: ARIA: 2008 Update. Allergy. 2008;63:8-160. doi:10.1111/j.1398-9995.2007.01620.x

5. Meltzer EO, Blaiss MS, Derebery MJ, et al. Burden of allergic rhinitis: results from the Pediatric Allergies in America survey. $J$ Allergy Clin Immunol. 2009;124(3):S43-S70. doi:10.1016/j.jaci.20 09.05 .013

6. Institute for Clinical Systems Improvement. Guideline: nonInfectious Rhinitis - Treatment for Allergic Rhinitis. Available from: https://www.icsi.org/guideline/respiratory-illness/non-infec tious-rhinitis-treatment-for-allergic-rhinitis/. Accessed January 25, 2021.

7. Cox L, Nelson H, Lockey R, et al. Allergen immunotherapy: a practice parameter third update. J Allergy Clin Immunol. 2011;127 (1):S1-S55. doi:10.1016/j.jaci.2010.09.034

8. Canonica GW, Durham SR Allergen Immunotherapy for allergic rhinitis and asthma: a Synopsis; 2016. Available from: https://www. worldallergy.org/education-and-programs/education/allergic-diseaseresource-center/professionals/allergen-immunotherapy-a-synopsis. Accessed November 13, 2020.

9. AAAAI. American Academy of Allergy Asthma \& Immunology; 2020. Available from: https://www.aaaai.org. Accessed November 12, 2020.

10. Durham SR, Emminger W, Kapp A, et al. SQ-standardized sublingual grass immunotherapy: confirmation of disease modification 2 years after 3 years of treatment in a randomized trial. J Allergy Clin Immunol. 2012;129(3):717-725.e5. doi:10.1016/j.jaci.2011.12.973

11. Bachert C, Larché M, Bonini S, et al. Allergen immunotherapy on the way to product-based evaluation - a WAO statement. World Allergy Organ J. 2015;8:29. doi:10.1186/s40413-015-0078-8

12. Jutel M, Akdis CA. Immunological mechanisms of allergen-specific immunotherapy. Allergy. 2011;66(6):725-732. doi:10.1111/j.13989995.2011.02589.x

13. Bernstein DI, Bardelas JA, Svanholm Fogh B, Kaur A, Li Z, Nolte H. A practical guide to the sublingual immunotherapy tablet adverse event profile: implications for clinical practice. Postgrad Med. 2017;129(6):590-597. doi:10.1080/00325481.2017.1302306

14. United Healthcare. Sublingual Immunotherapy.; 2020. Available from: https://www.uhcprovider.com/content/dam/provider/docs/pub lic/policies/comm-medical-drug/sublingual-liquid-immunotherapy. pdf. Accessed February 19, 2021.

15. U.S. Food and Drug Administration. Allergenics; 2021. Available from: https://www.fda.gov/vaccines-blood-biologics/allergenics. Accessed February 19, 2021.

16. Cox L, Calderon MA. Subcutaneous specific immunotherapy for seasonal allergic rhinitis: a review of treatment practices in the US and Europe. Curr Med Res Opin. 2010;26(12):2723-2733. doi:10. $1185 / 03007995.2010 .528647$

17. Elliott J, Kelly SE, Johnston A, Skidmore B, Gomes T, Wells GA. Allergen immunotherapy for the treatment of allergic rhinitis and/or asthma: an umbrella review. CMAJ Open. 2017;5(2):E373-E385. doi:10.9778/cmajo.20160066 
18. Jutel M, Agache I, Bonini S, et al. International consensus on allergy immunotherapy. J Allergy Clin Immunol. 2015;136(3):556-568. doi:10.1016/j.jaci.2015.04.047

19. Tankersley M, Han JK, Nolte H. Clinical aspects of sublingual immunotherapy tablets and drops. Ann Allergy Asthma Immunol. 2020;124(6):573-582. doi:10.1016/j.anai.2019.12.025

20. U.S. Department of Health and Human Services, Food and Drug Administration, Center for Drug Evaluation and Research (CDER), Center for Biologics Evaluation and Research (CBER). Patient-Focused Drug Development: collecting Comprehensive and Representative Input (Guidance for Industry, Food and Drug Administration Staff, and Other Stakeholders); 2020. Available from: https://www.fda.gov/media/139088/ download. Accessed February 8, 2021.

21. Brazier JE, Dixon S, Ratcliffe J. The Role of Patient Preferences in CostEffectiveness Analysis: a Conflict of Values? PharmacoEconomics. 2009;27(9):705-712. doi:10.2165/11314840-000000000-00000

22. Chester JG, Bremberg MG, Reisacher WR. Patient preferences for route of allergy immunotherapy: a comparison of four delivery methods: patient preference for allergy immunotherapy. Int Forum Allergy Rhinol. 2016;6(5):454-459. doi:10.1002/alr.21707

23. Damm K, Volk J, Horn A, et al. Patient preferences in allergy immunotherapy (AIT) in Germany - a discrete-choice-experiment. Health Econ Rev. 2016;6(1):32. doi:10.1186/s13561-016-0110-x

24. Sivam A, Tankersley M. Perception and practice of sublingual immunotherapy among practicing allergists in the United States. Ann Allergy Asthma Immunol. 2019;122(6):623-629.e2. doi:10.1016/j. anai.2019.03.023

25. Bridges JFP, Hauber AB, Marshall D, et al. Conjoint Analysis Applications in Health - a Checklist: a Report of the ISPOR Good Research Practices for Conjoint Analysis Task Force. Value Health. 2011;14(4):403-413. doi:10.1016/j.jval.2010.11.013

26. Ryan M. Using conjoint analysis to elicit preferences for health care. BMJ. 2000;320(7248):1530-1533. doi:10.1136/bmj.320.7248.1530

27. Reed Johnson F, Lancsar E, Marshall D, et al. Constructing Experimental Designs for Discrete-Choice Experiments: report of the ISPOR Conjoint Analysis Experimental Design Good Research Practices Task Force. Value Health. 2013;16(1):3-13. doi:10.1016/j.jval.2012.08.2223

28. Federal Drug Administration. Patient Preference Information: voluntary Submission, Review in Premarket Approval Applications, Humanitarian Device Exemption Applications, and de Novo Requests, and Inclusion in Decision Summaries and Device Labeling Guidance for Industry, Food and Drug Administration Staff, and Other Stakeholders; 2016. Available from: https:/www. fda.gov/media/92593/download. Accessed January 29, 2021.

29. Dahl R, Roberts G, de Blic J, et al. SQ grass sublingual allergy immunotherapy tablet for disease-modifying treatment of grass pollen allergic rhinoconjunctivitis. Allergy Asthma Proc. 2016;37(2):92104. doi:10.2500/aap.2016.37.3937
30. The Kaiser Family Foundation. Employer Health Benefits Survey 2018 (Annual Survey); 2018. Available from: http://files.kff.org/ attachment/Report-Employer-Health-Benefits-Annual-Survey-2018. Accessed March 9, 2021.

31. Ibrahim SA. Patient Preference as a Barrier to Needed Care. Am J Public Health. 2015;105(4):613-614. doi:10.2105/AJPH.2015.30 2603

32. Maloney J, Berman G, Gagnon R, et al. Sequential Treatment Initiation with Timothy Grass and Ragweed Sublingual Immunotherapy Tablets Followed by Simultaneous Treatment Is Well Tolerated. J Allergy Clin Immunol Pract. 2016;4(2):301-309. e2. doi:10.1016/j.jaip.2015.11.004

33. Blaiss MS, Steven GC, Bender B, Bukstein DA, Meltzer EO, Winders T. Shared decision making for the allergist. Ann Allergy Asthma Immunol. 2019;122(5):463-470. doi:10.1016/j.anai.2018. 08.019

34. Field K, Blaiss MS. Sublingual Versus Subcutaneous Immunotherapy for Allergic Rhinitis: what Are the Important Therapeutic and RealWorld Considerations? Curr Allergy Asthma Rep. 2020;20(9):45. doi:10.1007/s11882-020-00934-4

35. Winders T, DuBuske L, Bukstein DA, Meltzer EO, Wallace D, Rance $\mathrm{K}$. Shifts in allergy practice in a COVID-19 world: implications of pre-COVID-19 national health care provider and patient surveys of treatments for nasal allergies. Allergy Asthma Proc. 2021;42(4):301309. doi:10.2500/aap.2021.42.210035

36. Arbes Jr. SJ, Gergen PJ, Elliott L, Zeldin DC. Prevalences of positive skin test responses to 10 common allergens in the US population: results from the Third National Health and Nutrition Examination Survey. J Allergy Clin Immunol. 2005;116(2):377-383. doi:10.1016/j. jaci.2005.05.017

37. Cox L, Jacobsen L. Comparison of allergen immunotherapy practice patterns in the United States and Europe. Ann Allergy Asthma Immunol. 2009;103(6):451-460. doi:10.1016/S1081-1206(10)60259-1

38. Marogna M, Spadolini I, Massolo A, et al. Effects of sublingual immunotherapy for multiple or single allergens in polysensitized patients. Ann Allergy Asthma Immunol. 2007;98(3):274-280. doi:10.1016/S1081-1206(10)60718-1

39. Varney VA, Edwards J, Tabbah K, Brewster H, Mavroleon G, Frew AJ. Clinical efficacy of specific immunotherapy to cat dander: a double-blind placebo-controlled trial. Clin Exp Allergy. 1997;27 (8):860-867. doi:10.1111/j.1365-2222.1997.tb01225.x
Patient Preference and Adherence

\section{Publish your work in this journal}

Patient Preference and Adherence is an international, peer-reviewed, open access journal that focusing on the growing importance of patient preference and adherence throughout the therapeutic continuum. Patient satisfaction, acceptability, quality of life, compliance, persistence and their role in developing new therapeutic modalities and compounds to optimize clinical outcomes for existing disease states are major areas of interest for the journal. This journal has been accepted for indexing on PubMed Central. The manuscript management system is completely online and includes a very quick and fair peer-review system, which is all easy to use. Visit http:// www.dovepress.com/testimonials.php to read real quotes from published authors. 